\title{
Goq Regulates the Development of Rheumatoid Arthritis by Modulating Th1 Differentiation
}

\author{
Dashan Wang, ${ }^{1}$ Yuan Liu, ${ }^{2}$ Yan Li, ${ }^{2}$ Yan $\mathrm{He}^{2}$ Jiyun Zhang, ${ }^{3}$ and Guixiu Shi ${ }^{2}$ \\ ${ }^{1}$ Molecular Biology Research Center, Key Medical Health Laboratory for Laboratory Medicine of Shandong Province, \\ Department of Laboratory Medicine, Shandong Medical College, Linyi, Shandong 276000, China \\ ${ }^{2}$ Department of Rheumatology and Clinical Immunology, The First Affiliated Hospital of Xiamen University, Xiamen, \\ Fujian 361003, China \\ ${ }^{3}$ Key Medical Health Laboratory for Laboratory Medicine of Shandong Province, Department of Laboratory Medicine, \\ Shandong Medical College, Linyi, Shandong 276000, China
}

Correspondence should be addressed to Guixiu Shi; gshi@xmu.edu.cn

Received 28 October 2016; Revised 16 December 2016; Accepted 20 December 2016; Published 19 January 2017

Academic Editor: Qingdong Guan

Copyright (C) 2017 Dashan Wang et al. This is an open access article distributed under the Creative Commons Attribution License, which permits unrestricted use, distribution, and reproduction in any medium, provided the original work is properly cited.

\begin{abstract}
The $\mathrm{G} \alpha \mathrm{q}$-containing $\mathrm{G}$ protein, an important member of $G_{\mathrm{q} / 11}$ class, is ubiquitously expressed in mammalian cells. $\mathrm{G} \alpha \mathrm{q}$ has been found to play an important role in immune regulation and development of autoimmune disease such as rheumatoid arthritis (RA). However, how $\mathrm{G} \alpha \mathrm{q}$ participates in the pathogenesis of RA is still not fully understood. In the present study, we aimed to find out whether $\mathrm{G} \alpha \mathrm{q}$ controls RA via regulation of Thl differentiation. We observed that the expression of $\mathrm{G} \alpha \mathrm{q}$ was negatively correlated with the expression of signature Thl cytokine (IFN- $\gamma$ ) in RA patients, which suggests a negative role of G $\alpha$ q in differentiation of Th1 cells. By using G $\alpha \mathrm{q}$ knockout (Gnaq-/-) mice, we demonstrated that loss of G $\alpha \mathrm{q}$ led to enhanced Th1 cell differentiation. G $\alpha \mathrm{q}$ negative regulated the differentiation of Thl cell by modulating the expression of T-bet and the activity of STAT4. Furthermore, we detected the increased ratio of Th1 cells in Gnaq-/- bone marrow (BM) chimeras spontaneously developing inflammatory arthritis. In conclusion, results presented in the study demonstrate that loss of $\mathrm{G} \alpha \mathrm{q}$ promotes the differentiation of Thl cells and contributes to the pathogenesis of RA.
\end{abstract}

\section{Introduction}

Guanine nucleotide-binding proteins (G proteins) are the most widely used signal transducers in mammalian cells. G proteins transmit signals from ligand activated G protein coupled receptors (GPCRs) to effector proteins and then regulate many biological functions [1]. GPCR ligands include numerous hormones, neurotransmitters, peptides, small proteins, and lipid molecules. Accordingly, biological functions mediated by G proteins and GPCRs are diverse, including behavioral, sensory functions, appetite control, metabolism, development, inflammation, and chemotaxis [2]. The heterotrimeric $G$ proteins are composed of $\alpha$-subunit that binds and hydrolyzes GTP, as well as $\beta$ - and $\gamma$-subunits that form a functional complex. The $\alpha$-subunits of $\mathrm{G}$ proteins are highly specialized and induce many different downstream signals. Based on the sequence similarity of their $\alpha$-subunits, $G$ proteins can be classified into four subfamilies: Gi, Gs, $\mathrm{Gq} / 11$, and G12/13. G $\alpha \mathrm{q}$, which is the $\alpha$-subunit Gq protein, is encoded by GNAQ [3]. The G $\alpha$ q containing G protein initially attracted our attention for its important role in cardiovascular system in 1990s [4]. In recent years, studies have also demonstrated that $\mathrm{G} \alpha \mathrm{q}$ are involved in immune regulation and autoimmune disease. Our previous studies reported that $\mathrm{G} \alpha \mathrm{q}$ regulated migration of dendritic cells and survival of B cells and T cells [5-7]. More important, Gnaq-/- bone marrow (BM) chimeras with G $\alpha$ q deficiency only in their immune system could spontaneously develop symptoms of arthritis similar to RA [6]. We also reported that the protein and mRNA expression levels of $\mathrm{G} \alpha \mathrm{q}$ in peripheral blood lymphocytes (PBLs) of rheumatoid arthritis (RA) patients were significantly lower compared with healthy 
TABLE 1: Demographic and clinical characteristics of the patients with rheumatoid arthritis (RA) and healthy control subjects.

\begin{tabular}{lcc}
\hline & $\begin{array}{c}\text { RA patients } \\
(n=30)\end{array}$ & $\begin{array}{c}\text { Healthy controls } \\
(n=30)\end{array}$ \\
\hline Age, mean (range) years & $46.1(33-75)$ & $45.5(28-64)$ \\
Male : female & $5: 25$ & $8: 22$ \\
C-reactive protein $(\mathrm{mg} / \mathrm{L})$ & $15.9(1.1-90.6)$ & - \\
Rheumatoid factor $(\mathrm{IU} / \mathrm{mL})$ & $192.0(6-943)$ & - \\
DAS28* mean (range) score & $2.99(1.12-5.07)$ & - \\
\hline
\end{tabular}

${ }^{*}$ DAS28 $=28$ joints' disease activity score.

controls [8]. These results indicated a critical role of $\mathrm{G} \alpha \mathrm{q}$ in the pathogenesis of RA.

Rheumatoid arthritis (RA) is the most common systemic autoimmune disease characterized by chronic inflammation of joint synovial tissue and subsequent destruction of associated bone, cartilage, and soft tissues [3]. Although the etiology of RA is still not fully understood, T cells are thought to play a central role in joint inflammation and disease progression $[9,10]$. Among of them, $\mathrm{T}$ helper 1 (Th1) cells have been found to play an important role in RA in several studies. Th1 cells infiltrate the synovium, secret proinflammatory cytokines, and promote macrophage and neutrophil infiltration [11-13]. Our previous study indicated that $\mathrm{G} \alpha \mathrm{q}$ is associated with RA. However, how $\mathrm{G} \alpha \mathrm{q}$ is involved in the initiation and development of RA is not fully studied. In the current study, we will study the role of $\mathrm{G} \alpha \mathrm{q}$ in Thl cell differentiation and RA. First, we studied the relationship between $\mathrm{G} \alpha \mathrm{q}$ and hallmark Thl cytokine (IFN- $\gamma$ ) in RA patients. Then, we investigated the role of $\mathrm{G} \alpha \mathrm{q}$ in Th1 differentiation and inflammatory arthritis by using Gnaq-/mice. We found that $\mathrm{G} \alpha \mathrm{q}$ was negatively associated with signature Th1 cytokine (IFN- $\gamma$ ) in RA patients, which suggested that $\mathrm{G} \alpha \mathrm{q}$ might be involved in Th1 cells differentiation. In consistent with the result we observed in RA patients, the percentage of Th1 cells was significantly increased in Gnaq-/BM chimeras which spontaneously developed inflammatory arthritis. Moreover, our results showed that the deficiency of G $\alpha \mathrm{q}$ heightened the differentiation of Thl cells via T-bet and STAT4 by using Gnaq-/- mice. Here we show that $\mathrm{G} \alpha \mathrm{q}$ might be involved in Thl cells differentiation and further participate in the pathogenesis of RA.

\section{Material and Methods}

2.1. Patients. A total of $30 \mathrm{RA}$ patients fulfilling the American College of Rheumatology 1987 revised criteria [14] were recruited from the outpatient clinic of the Department of Rheumatology and Clinical Immunology, The First Affiliated Hospital of Xiamen University. 30 sex-matched and agematched healthy volunteers were recruited as healthy controls. The study was done after obtaining written informed consent of patients and approval of the Ethics Committee of The First Affiliated Hospital of Xiamen University. The demographic and clinical features of healthy controls and patients with RA were summarized in Table 1.
2.2. Animals. C57BL/6J and Gnaq-/- mice $(N>5$ backcrossed to C57BL/6J) were maintained in a pathogen-free animal facility of Xiamen University and used between 6 and 8 weeks of age. Gnaq-/- mice are difficult to study as they are born runted and exhibit motor defects. In order to analyze the role of $\mathrm{G} \alpha \mathrm{q}$ in development of arthritis, we generated BM chimeric mice. BM chimeras were generated by irradiating recipient mice with a split dose of 800 Rads and then reconstituting the recipients with $1 \times 10^{6} \mathrm{BM}$ cells from C57BL/6 or Gnaq-/- donors. All experimental procedures involving mice were approved by the Animal Care and Use Committee of Xiamen University.

2.3. Blood Samples. Peripheral blood samples from RA patients and healthy volunteers were collected into collection tubes containing $0.2 \mathrm{~mL}$ sodium heparin. Peripheral blood mononuclear cells (PBMCs) were isolated from peripheral blood samples by standard density-gradient centrifugation using Ficoll-Paque Plus (Axis-Shied).

\subsection{T Cell Purification and In Vitro Th1 Cells Induction.} Spleens from WT and Gnaq-/- mice were passed through a fine nylon mesh to obtain single cell suspension. Red blood cells (RBCs) were lysed using ACK lysis buffer. CD $4^{+} \mathrm{CD} 62 \mathrm{~L}^{+}$ cells were isolated using a negative selection step and a positive selection step. First, $\mathrm{CD} 4^{+} \mathrm{T}$ cells were purified using negative selection with biotinylated Abs against B220, MHC-II, CD8, CD49b, CD11c, and CD11b (eBiosciences); second, $\mathrm{CD} 4{ }^{+} \mathrm{CD} 62 \mathrm{~L}^{+}$cells were isolated and then by positive selection using biotinylated Abs against CD62L (eBioscience), followed by streptavidin conjugated magnetic beads (Miltenyi) [15]. Purity, as assessed by flow cytometry, was $>92 \%$. Purified naïve $\mathrm{CD}^{+} \mathrm{T}$ cells were stimulated with precoated anti-CD3/CD28 $(3 \mu \mathrm{g} / \mathrm{mL})$ for 5 days, with mouse IL-12 $(20 \mathrm{ng} / \mathrm{mL})$, mouse IL-2 (20 ng/mL) (PeproTech), and anti-IL-4 $(10 \mu \mathrm{g} / \mathrm{mL})$ (eBioscience) added to the cultures [16].

2.5. Flow Cytometry and Intracellular Staining. Cells were collected and stimulated with PMA $(25 \mathrm{ng} / \mathrm{mL})$ and ionomycin $(1 \mu \mathrm{g} / \mathrm{mL})$ in the presence of $1 \mu \mathrm{g} / \mathrm{mL}$ monesin (Sigma-Aldrich) for 4 hours. Cells were then fixed, permeabilized by using Fixation/Permeabilization Solution Kit (eBioscience) according to the manufacturer's instructions, and stained with FITC-conjugated anti-IFN- $\gamma$, PEconjugated anti-phospho-STAT4, or PE-cy7-conjugated antiT-bet (eBioscience). In order to stain Th1 cells in mice, single cell suspension was deprived from spleen of WT and Gnaq-/- chimeric mice, stimulated with PMA, ionomycin, and monensin for 4 hour. After culture, cells were stained with PE-conjugated anti-CD4, followed by intracellular staining with FITC-conjugated anti-IFN- $\gamma$. Cells were analyzed on Cytomic FC500 (Beckman Coulter), and data were analyzed using FlowJo (Tree Star).

2.6. Real-Time PCR Analysis. Total RNA was isolated from PBMCs using TRIzol (Invitrogen). Complementary DNA was synthesized using reverse transcription reagent kits according to manufacturer's instructions (Bio-Rad). The 


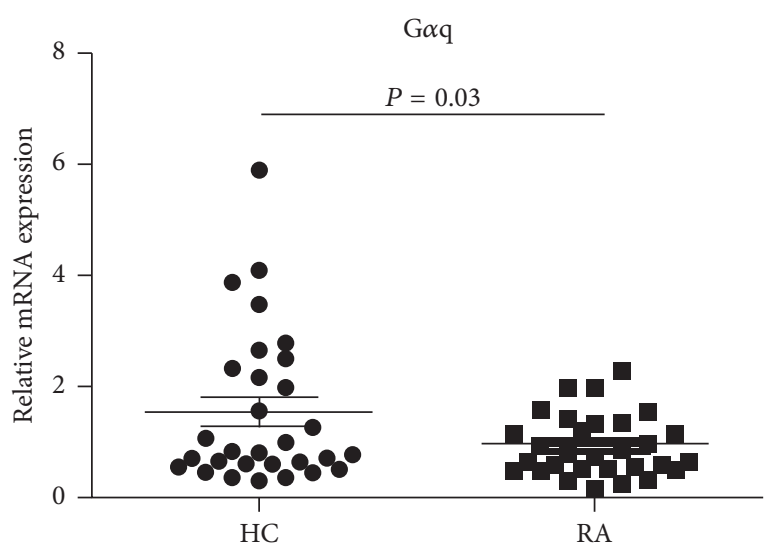

(a)

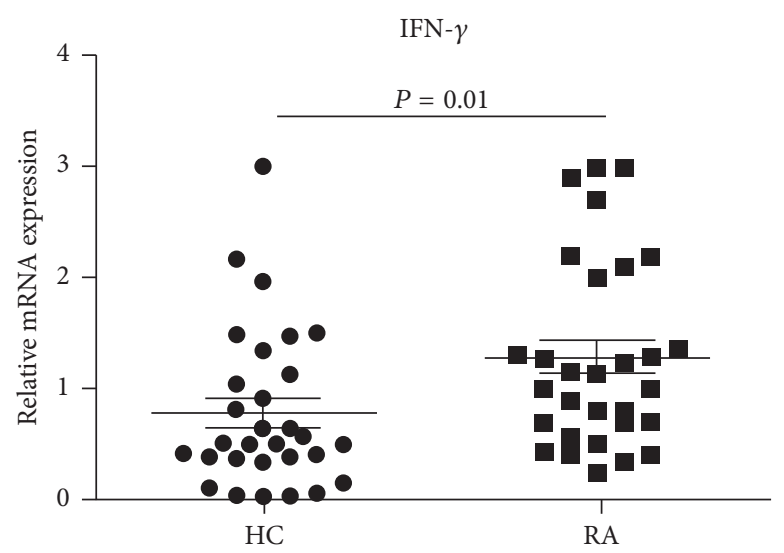

(b)

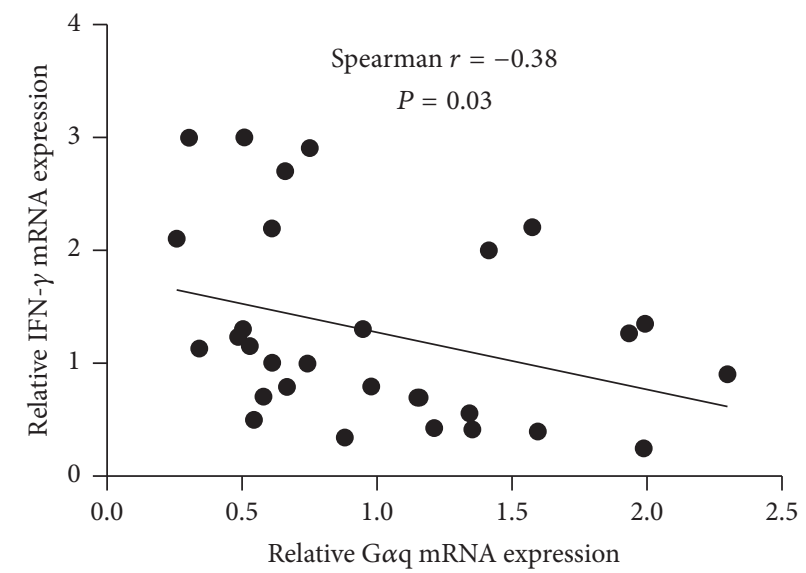

(c)

FIgURE 1: Correlation of mRNA expression level of G $\alpha$ q and IFN- $\gamma$. The mRNA expression of G $\alpha \mathrm{q}$ and IFN- $\gamma$ was detected by real-time PCR. Relative (a) G $\alpha$ q and (b) IFN- $\gamma$ mRNA expression in PBMCs from patients with rheumatoid arthritis (RA; $n=30$ ) and healthy controls (HC; $n=30$ ). Bars show the mean and standard deviation (SD). $P$ value was determined by Mann-Whitney test. (c) The correlation between G $\alpha \mathrm{q}$ mRNA expression level and IFN- $\gamma$ mRNA expression level in RA patients $(n=30)$ was determined by using Spearman test.

expression levels of IFN- $\gamma$ and $\mathrm{G} \alpha \mathrm{q}$ were determined by real-time quantitative PCR. A $10 \mu \mathrm{L}$ SsoFast EvaGreen PCR reaction system was used. It includes $2 \mu \mathrm{L}$ of $\mathrm{cDNA}$, $2.6 \mu \mathrm{L}$ ddH2O, $0.2 \mu \mathrm{L}$ of sense primer, $0.2 \mu \mathrm{L}$ of antisense primer, and $5 \mu \mathrm{L}$ SsoFast EvaGreen Supermix (Bio-Rad). The PCR reaction conditions were as follows: $95^{\circ} \mathrm{C}$ for $1 \mathrm{~min}$, then 40 cycles of $95^{\circ} \mathrm{C}$ for $10 \mathrm{~s}, 60^{\circ} \mathrm{C}$ for $10 \mathrm{~s}$, and $72^{\circ} \mathrm{C}$ for $10 \mathrm{~s}$. Reactions were performed with $\mathrm{iQ}^{\mathrm{TM}} 5$ realtime PCR Detection Systems (Bio-Rad). Target gene expressions were normalized to GAPDH and relative expression was calculated using the $2^{-\Delta \Delta C t}$ method. The following primers were used: GNAQ, 5'-GTTGATGTGGAGAAGGTGTCTG-3' and 5'-GTAGGCAGGTAGGCAGGGT$3^{\prime}$; IFNG, $5^{\prime}$-GATGACTTCGAAAAGCTGACTAATTATTC- $3^{\prime}$ and $5^{\prime}$-GTTCAGCCATCACACTTGGATGAG- $3^{\prime}$ GAPDH, $5^{\prime}$-GTGAACCATGAGAAGTATGACAAC- $3^{\prime}$ and $5^{\prime}$-CATGAGTCCTTCCACGATACC- $3^{\prime}$.

2.7. Enzyme-Linked Immunosorbent Assay (ELISA). The concentration of mouse IFN- $\gamma$ was detected using commercially available ELISA kits according to the manufacturer's instructions (BioLegend). Absorbance was measured with an ELISA microplate reader at $450 \mathrm{~nm}$.

2.8. Statistical Analysis. Data were analyzed with Prism 5.01 software (GraphPad Software). Statistical differences between WT and Gnaq-/- groups were determined by Student's $t$ test. Statistical differences between healthy volunteers and RA were determined by Mann-Whitney $U$ test. The correlation between $\mathrm{G} \alpha \mathrm{q}$ and IFN- $\gamma$ was analyzed using Spearman test. $P$ value $<0.05$ was considered to be statistically significant.

\section{Results}

3.1. G $\alpha$ q and IFN- $\gamma$ Were Negatively Correlated in RA Patients. A paper of our group has reported that expression levels of $\mathrm{G} \alpha \mathrm{q}$ were significantly decreased in RA patients and negatively correlated with disease activity [8]. Our previous results also showed that Gnaq-/- BM chimeric mice spontaneously developed inflammatory arthritis, indicating that $\mathrm{G} \alpha \mathrm{q}$ might be involved in development of RA [6]. Th1 cell is recognized as a main effector cell in RA progression [17, 18]; 


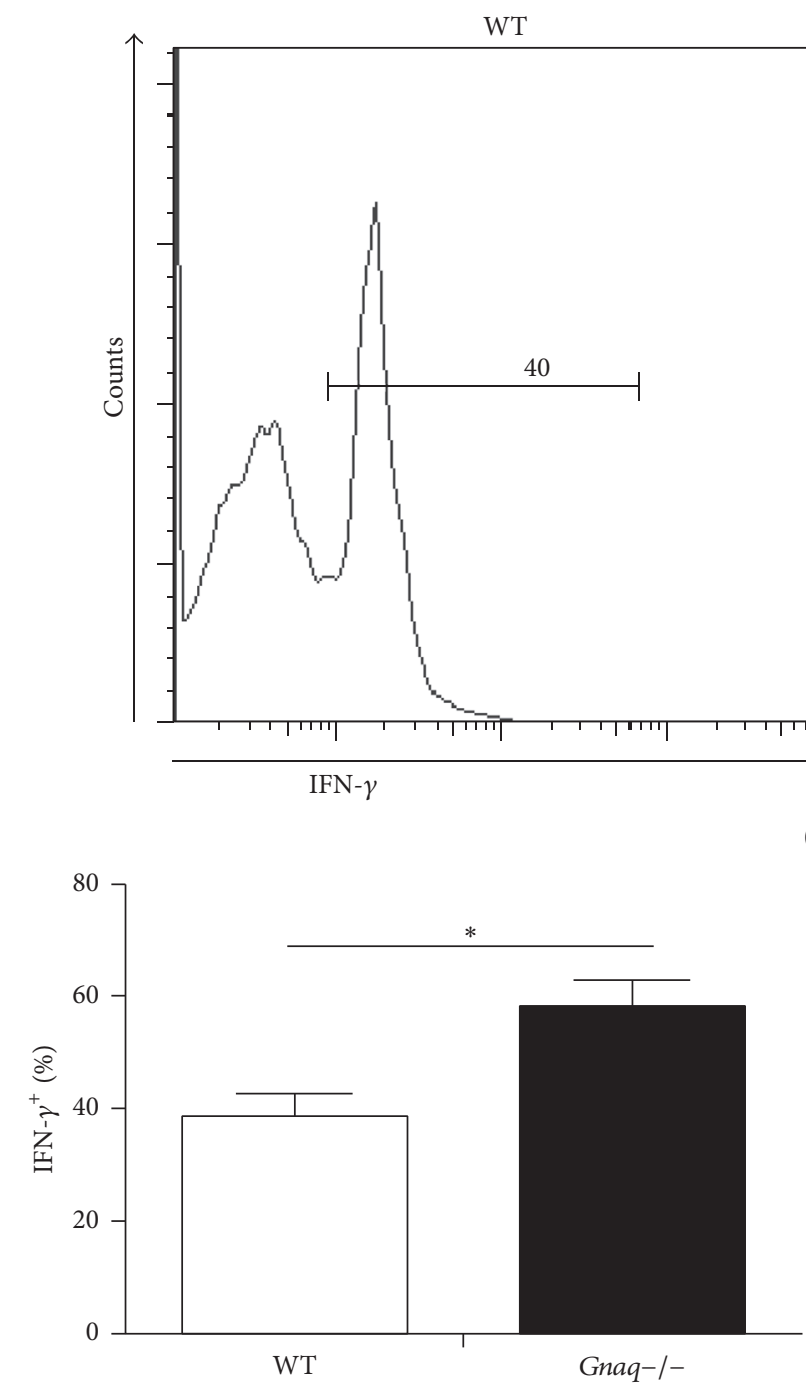

(b)

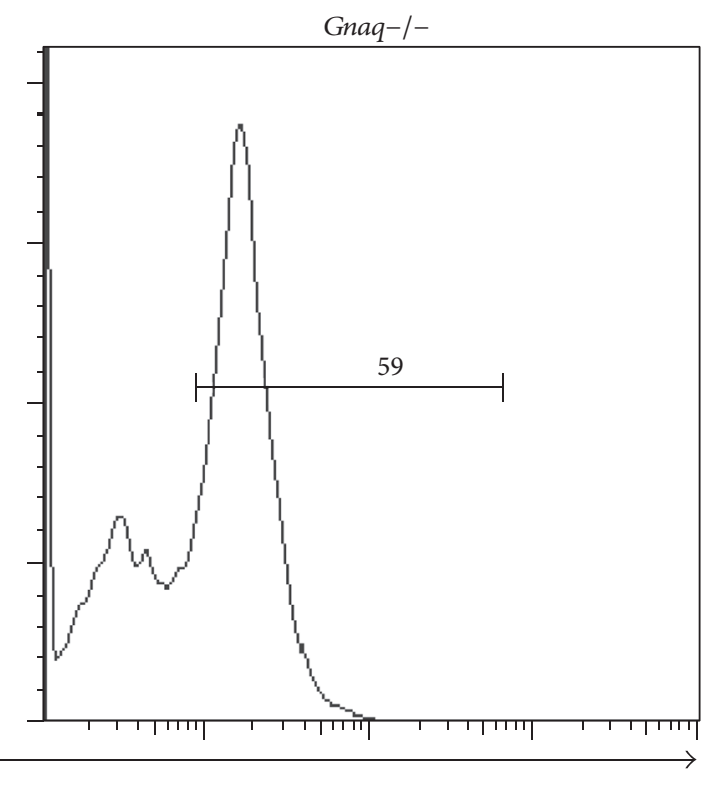

(a)

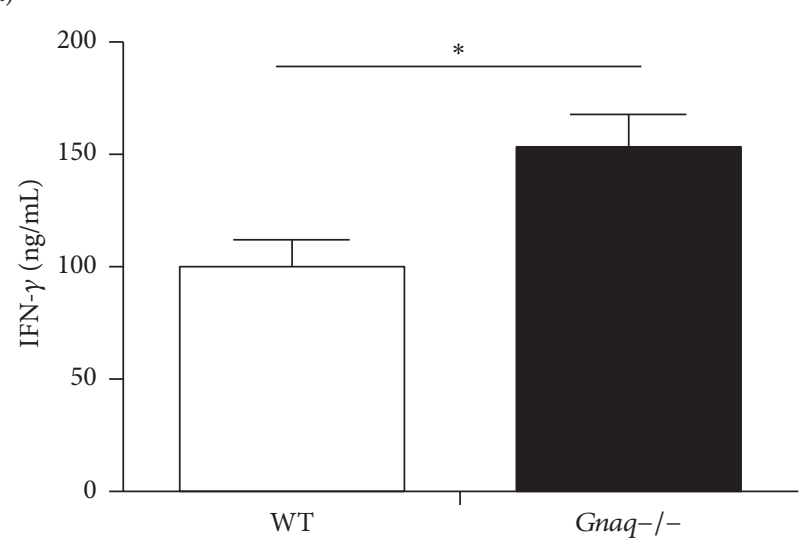

(c)

FIGURE 2: Loss of G $\alpha$ q enhances the differentiation of Th1 cells. Purified naïve CD4 ${ }^{+} \mathrm{T}$ cells from WT and Gnaq-/- mice were stimulated with anti-CD3/CD28 $(3 \mu \mathrm{g} / \mathrm{mL})$, in the presence of mouse IL-12 $(20 \mathrm{ng} / \mathrm{mL})$, mouse IL-2 $(20 \mathrm{ng} / \mathrm{mL})$, and anti-IL-4 $(10 \mu \mathrm{g} / \mathrm{mL})$ for five days. Cells were harvested and analyzed. (a) WT and Gnaq-/- CD4 ${ }^{+}$T cells were stimulated with PMA, ionomycin, and monensin, fixed, permeabilized, and stained with FITC-conjugated anti-IFN- $\gamma$, followed by flow cytometry. (b) The percentage of IFN- $\gamma^{+}$cells was calculated. (c) IFN- $\gamma$ secretion was detected by ELISA. Cultured CD $4^{+} \mathrm{T}$ cells were harvested, adjusted to same concentration, and stimulated by anti-CD3/CD28 $(1 \mu \mathrm{g} / \mathrm{mL})$ for 24 hours. Supernatants were collected for ELISA assay. All data are presented as mean $\pm \mathrm{SD} ;{ }^{*} P<0.05, n=3$. The result is representative of three independent experiments.

thus, whether G $\alpha \mathrm{q}$ can regulate Th1 cell response and further participates in development of RA attracts our interests. We first investigated the association of $\mathrm{G} \alpha \mathrm{q}$ and hallmark Thl cytokine (IFN- $\gamma$ ) in RA patients. We detected G $\alpha \mathrm{q}$ and IFN- $\gamma$ mRNA expression in PBMCs from 30 RA patients and 30 healthy controls by real-time PCR. Results showed that $\mathrm{G} \alpha \mathrm{q}$ mRNA expression was significantly decreased and IFN- $\gamma$ mRNA expression was significantly increased in RA patients compared to healthy controls (Figures 1(a) and 1(b)). Moreover, we found a negative correlation between expression level of G $\alpha \mathrm{q}$ and IFN- $\gamma$ (Figure 1(c)). These data demonstrate that $\mathrm{G} \alpha \mathrm{q}$ was negatively associated with signature Thl cytokine (IFN- $\gamma$ ) in RA patients.
3.2. Loss of $\mathrm{G} \alpha q$ Enhanced the Differentiation of Th1 Cells. The result presented above encouraged us to study whether $\mathrm{G} \alpha \mathrm{q}$ regulates Th1 cell differentiation. In order to address this question, we used $\mathrm{G} \alpha \mathrm{q}$ knockout (Gnaq-/-) mice. Naïve $\mathrm{CD}^{+} \mathrm{T}$ cells were purified from spleen of Gnaq-/- and WT mice and incubated under Th1 differentiation condition. After 5-day culture, cells were harvested and analyzed by flow cytometry (Figure 2(a)). Intracellular staining showed higher frequency of IFN- $\gamma+$ cells in Gnaq-/- CD $4^{+} \mathrm{T}$ cell than WT group (Figure 2(b)). We also measured the level of IFN- $\gamma$ in supernatant by ELISA. Cultured CD $4^{+} \mathrm{T}$ cells were harvested, adjusted to same concentration, and stimulated by anti-CD3/CD28 $(1 \mu \mathrm{g} / \mathrm{mL})$ for 24 hours. Supernatants were 

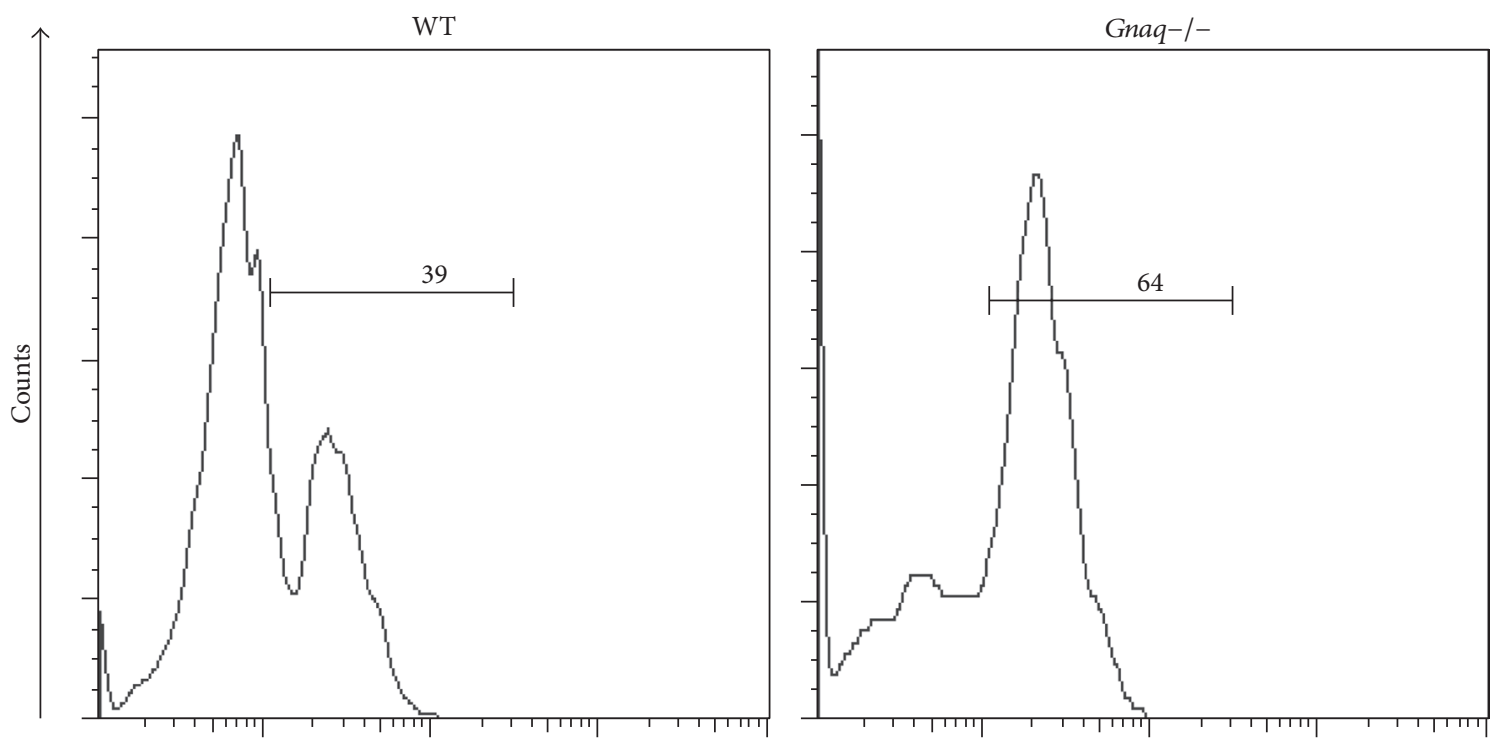

T-bet

(a)

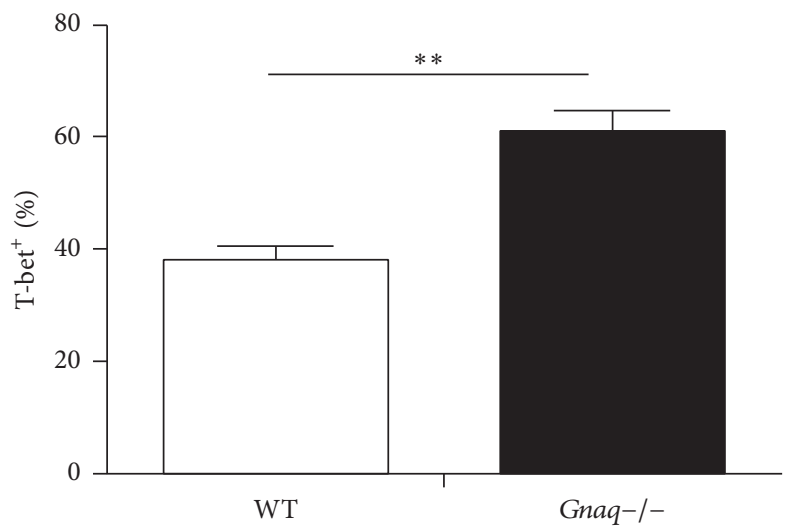

(b)

Figure 3: Loss of G $\alpha$ q enhances the expression of T-bet. (a) Purified naïve CD4 ${ }^{+} \mathrm{T}$ cells from WT and Gnaq-/- mice were stimulated with anti-CD3/CD28 $(3 \mu \mathrm{g} / \mathrm{mL})$, in the presence of mouse IL-12 $(20 \mathrm{ng} / \mathrm{mL})$, mouse IL-2 $(20 \mathrm{ng} / \mathrm{mL})$, and anti-IL-4 (10 $\mu \mathrm{g} / \mathrm{mL})$ for five days. Cells were harvested, fixed, permeabilized, and stained with PE-cy7-conjugated anti-T-bet and analyzed by flow cytometry. (b) The percentage of T-bet ${ }^{+}$cells was calculated. All data are presented as mean $\pm \mathrm{SD} ;{ }^{* *} P<0.05, n=3$. The result is representative of three independent experiments.

collected and cytokine concentrations were measured by ELISA assay. Result demonstrated that secretion level of IFN$\gamma$ was also much higher in Gnaq-/- CD $4^{+}$T cell (Figure 2(c)). These results showed that $\mathrm{G} \alpha \mathrm{q}$ regulates Th1 differentiation.

\subsection{Absence of Goq Heightened the Expression of T-Bet} and p-STAT4 in CD4 ${ }^{+} \mathrm{T}$ Cells. Results presented above identified a negative role of $\mathrm{G} \alpha \mathrm{q}$ in Th1 differentiation. Tbet, a Th1-specific $\mathrm{T}$ box transcription factor that controls the expression of IFN- $\gamma$, is a critical regulator for Th1 cell differentiation [19]. To explore underlying mechanism of the regulation of $\mathrm{G} \alpha \mathrm{q}$ in Thl differentiation, we next detected the status of T-bet in WT and Gnaq-/- $\mathrm{CD} 4^{+}$T cells under Th1 polarizing condition. After 5 days of induction, cells were harvested and expression of T-bet was analyzed by flow cytometry (Figure 3(a)). Result showed that expression level of T-bet was dramatically increased in Gnaq-/- CD $4^{+}$ T cells compared with WT CD4 ${ }^{+} \mathrm{T}$ cells (Figure 3(b)). As STAT4 is also a critical factor in Th1 differentiation, we further measured the phosphorylation of STAT4 by flow cytometry. The level of phospho-STAT4 was obviously higher in Gnaq-/- CD4 ${ }^{+} \mathrm{T}$ cells than WT controls (Figure 4). Therefore, results demonstrate that $\mathrm{G} \alpha \mathrm{q}$ regulates Th1 cell differentiation by modulating T-bet and STAT4 in Gnaq-/mice.

3.4. Percentage of Th1 Cells Was Increased in Gnaq-/- BM Chimeras Spontaneously Developing Arthritis. We have identified a negative correlation between G $\alpha \mathrm{q}$ and hallmark Th1 cytokine (IFN- $\gamma$ ) in RA patients and a negative role of $\mathrm{G} \alpha \mathrm{q}$ 


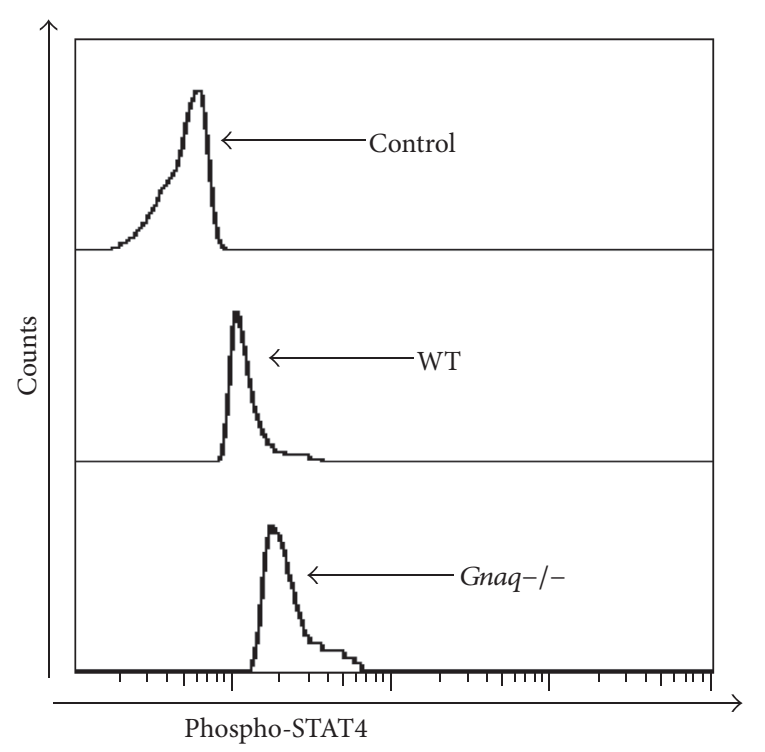

FIgUre 4: Loss of G $\alpha$ q enhances the activation of STAT4. Purified naïve $\mathrm{CD}^{+}$T cells from WT and Gnaq-/- mice were stimulated under Thl induction condition for 10 minutes. Cells were harvested, fixed, permeabilized, and stained with PE-conjugated anti-p-STAT4 and analyzed by flow cytometry. Data are representative of three independent experiments with similar results.

in Thl cell differentiation in Gnaq-/- mice. Meanwhile, our previous result has demonstrated that Gnaq-/- BM chimeric mice can develop symptoms of arthritis similar to RA. Based on these findings, we considered that it is important to determine whether homeostasis of Thl cell is disturbed in Gnaq-/- mice. Gnaq-/- mice are difficult when used in the current study as they are born runted and exhibit motor defects. In order to analyze the role of $\mathrm{G} \alpha \mathrm{q}$ in development of arthritis, we generated BM chimeric mice. As previous study, Gnaq-/- BM chimeras spontaneously developed symptom of inflammatory arthritis 3.5 months after BM reconstruction. We measured the percentage of Thl cells in the spleen of autoimmune prone Gnaq-/- BM chimeras and WT $\mathrm{BM}$ chimeras 3.5 months after BM reconstruction by flow cytometry (Figure 5(a)). Single cell suspension was deprived from spleen of WT and Gnaq-/- BM chimeras, stimulated with PMA, monensin, and ionomycin for 4 hours. After culture, cells were stained with PE-conjugated anti-CD4, followed by intracellular staining with FITC-conjugated antiIFN- $\gamma$. Results showed that the percentage of Thl cells was significantly increased in Gnaq-/- BM chimeras compared with WT BM chimeras (Figure 5(b)). The spontaneously developed arthritis in Gnaq-/- BM chimeras might be partially attributed to increased $\mathrm{Th} 1$ response.

\section{Discussion}

In this study, we explored the role of $\mathrm{G} \alpha \mathrm{q}$ in Th1 differentiation and development of RA. We found that expression level of $\mathrm{G} \alpha \mathrm{q}$ and hallmark Thl cytokine (IFN- $\gamma$ ) was negatively related in RA patients and percentage of Thl cells was significantly increased in Gnaq-/- BM chimeras spontaneously developing arthritis. Furthermore, we demonstrated that G $\alpha \mathrm{q}$ negatively regulated Thl differentiation by modulating T-bet and STAT4 in Gnaq-/- mice.

$\mathrm{G} \alpha \mathrm{q}$ has been identified as an important factor in immune regulation in several studies. Moreover, we have showed that expression level of $\mathrm{G} \alpha \mathrm{q}$ was significantly decreased in RA patients and loss of $\mathrm{G} \alpha \mathrm{q}$ in mice leads to autoimmune arthritis $[6,8]$. However, the exact mechanism of how $\mathrm{G} \alpha \mathrm{q}$ is involved in the pathogenesis of RA has not been fully studied. RA is a chronic autoimmune disease characterized by joint synovial inflammation and destruction of the surrounding tissue [20]. Although it is still unclear how RA is initiated, $\mathrm{T}$ cells, particularly $\mathrm{CD} 4^{+} \mathrm{T}$ helper (Th), are considered to be critical to initiation and maintenance of this disease by secreting proinflammation cytokines that regulate immune reactivity and synovial inflammation [21, 22]. The two $\mathrm{CD}^{+}$Th subsets, Th1 cells which secrete IFN- $\gamma$ as their hallmark cytokine and Th17 cells which secret IL-17, have been recognized as critical factors in the pathogenesis of RA [23]. Although the newly discovered Th17 cells have been proved to be critical in the pathogenesis of RA, the important role of Thl cannot be dismissed. Numerous studies have demonstrated that Thl cells play an important role in promoting inflammation in RA [24]. In our study, we found a negative correlation between expression level of $\mathrm{G} \alpha \mathrm{q}$ and IFN- $\gamma$, which suggests that $\mathrm{G} \alpha \mathrm{q}$ might negatively regulate Thl differentiation in RA patients. A paper of our group reported that Gnaq-/- BM chimeras would exhibit manifestations of inflammatory arthritis 3.5 months after reconstitution. Besides, autoantibodies such as anti-nuclear $\mathrm{Ab}$ (ANA) and anti-double-stranded (ds) DNA Ab were significantly increased in Gnaq-/- BM chimeras [6]. The symptom of inflammatory arthritis in Gnaq-/- BM chimeras is similar to RA in humans. What is more, Gnaq + /- mice have been used as mice model of autoimmune disease in a recent paper [25]. In line with results we observed in RA patients, the percentage of Th1 cells was significantly increased in spleen of Gnaq-/- BM chimeras spontaneously developing inflammatory arthritis. Taken together, these observations indicated that $\mathrm{G} \alpha \mathrm{q}$ negatively regulates Thl differentiation and partially contributed to the pathogenesis of RA.

The induction and maintenance of each $\mathrm{CD} 4^{+}$Th cell are mainly determined by cytokine environment at the time of naïve $\mathrm{T}$ cell activation [26]. Th1 cell polarization is usually induced in the presence of IL-12 and IFN- $\gamma$, which activate the expression of the master regulator transcription factors, such as T-bet and STAT4 (signal transducer and activator of transcription 4) [27]. T-bet can remodel the Ifng gene and promote IFN- $\gamma$ expression [28]; besides it can upregulate IL-12R $\beta 2$ expression [29], leading to enhanced Th1 cell expansion in response to IL-12. STAT4 is also an essential factor in regulation IL-12 signals and Th1 differentiation; the importance of this molecular in Th1 differentiation is demonstrated by STAT4 ${ }^{-/-}$mice [30]. Both STAT4 and T-bet are needed for maximal IFN- $\gamma$ production and while loss of either one will lead to disturbed IFN- $\gamma$ production [31]. In this study, our results showed that expressions of p-STAT4 and T-bet were both upregulated in Gnaq-/- $\mathrm{CD} 4^{+} \mathrm{T}$ cells. 

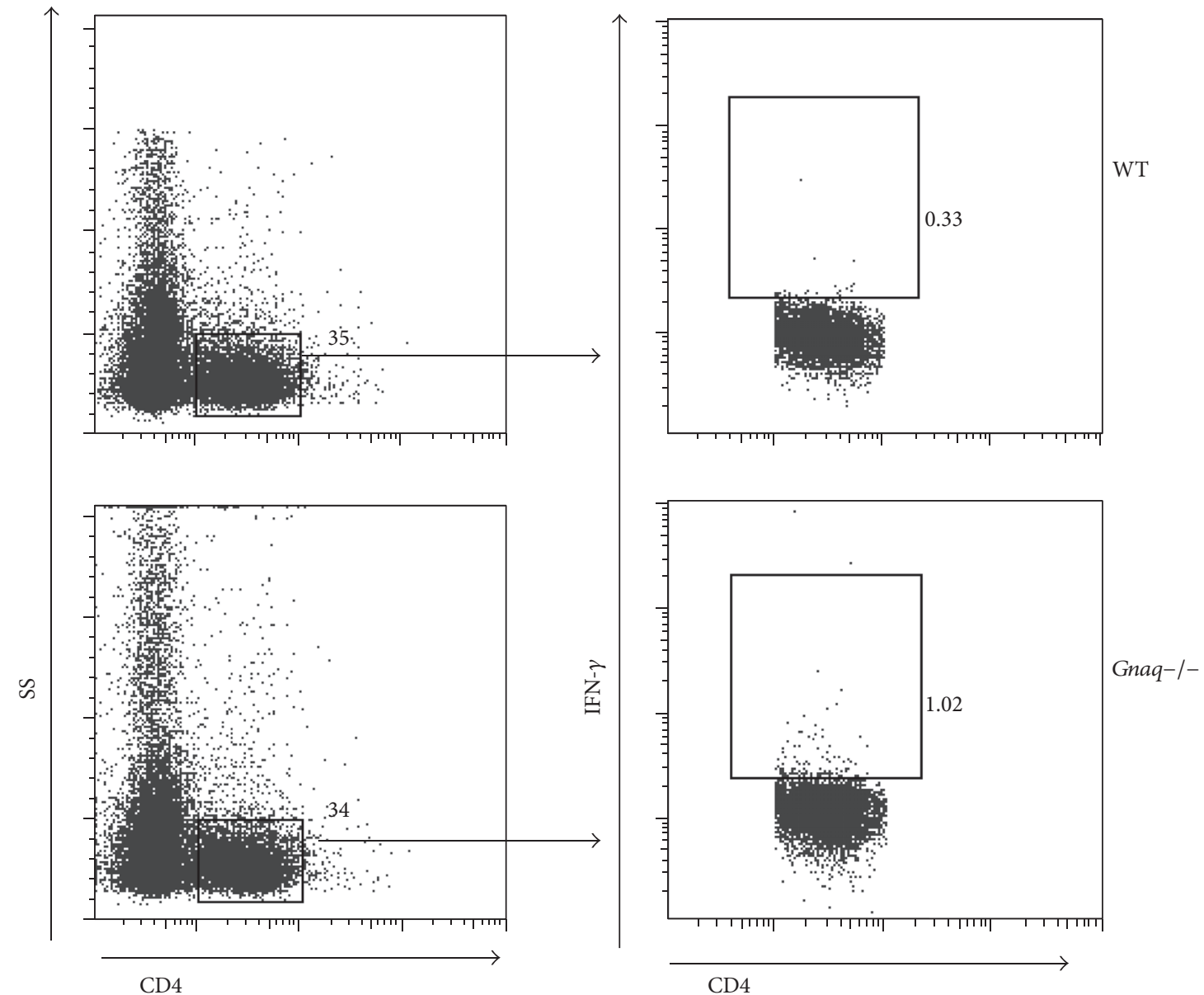

(a)

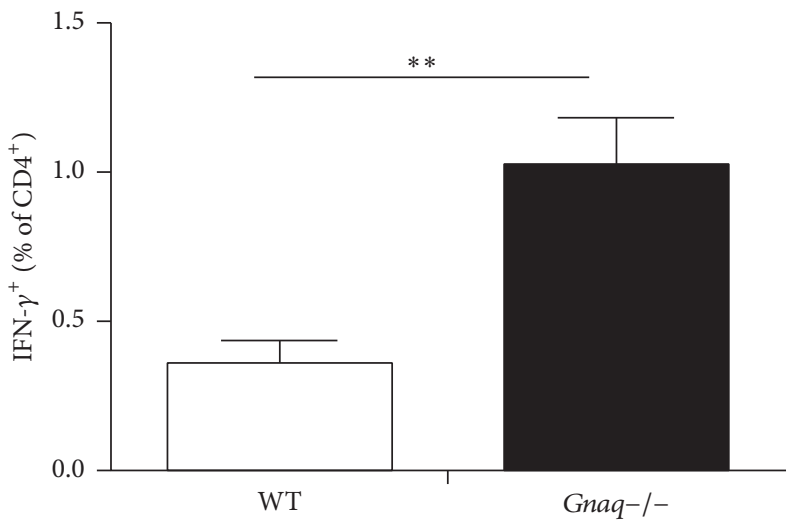

(b)

FIGURE 5: The percentage of Thl cells is increased in Gnaq-/- BM chimeras suffering from inflammatory arthritis. (a) Single cell suspension was deprived from spleen of Gnaq-/- BM chimeras suffering from inflammatory arthritis and WT controls, stimulated with PMA, ionomycin, and monensin for 4 hours. After culture, cells were stained with PE-conjugated anti-CD4, followed by intracellular staining with FITCconjugated anti-IFN- $\gamma$, and analyzed by flow cytometry. Gated on CD4 ${ }^{+}$cells. (b) The percentage of Th1 cells is presented as mean \pm SE, ${ }^{* *} P<0.05, n=3$. The result is representative of three independent experiments.

G $\alpha \mathrm{q}$ might regulate Th1 differentiation by modulating T-bet and STAT4. Nuclear factor of activated T cells (NFAT), a $\mathrm{Ca}^{2+}$ dependent transcription factor family, has been shown to be important in $\mathrm{T}$ cell differentiation. Sustained NFAT signaling promoted $\mathrm{CD} 4^{+} \mathrm{T}$ cells differentiate to Th1 cells in Th1-skewing conditions [32]. Another study demonstrates that STAT4 enhanced Th1 differentiation IFN- $\gamma$ expression by upregulating the binding of activator Protein-1 (AP-1) to the 
IFN- $\gamma$ promoter sequence [33]. Interestingly, one previous study reported that $\mathrm{G} \alpha \mathrm{q}$ knockdown in T cells significantly increased NFAT and AP-1 activity [34]. These data suggest that $\mathrm{G} \alpha \mathrm{q}$ might also regulate Th1 cell differentiation via NFAT/AP-1 signaling pathway.

\section{Conclusions}

Taken together, we demonstrated that $\mathrm{G} \alpha \mathrm{q}$ inhibited the differentiation of Thl cells and participated in pathogenesis of RA. G $\alpha$ q might regulate Thl cell differentiation via modulating activity of STAT- 4 and T-bet. This study provides a new insight into the pathogenesis of RA and suggests a novel therapeutic target for autoimmune disease.

\section{Competing Interests}

The authors declare no conflict of interests.

\section{Authors' Contributions}

Dashan Wang and Yuan Liu contributed equally to this work.

\section{Acknowledgments}

The work was supported by NSFC (National Natural Science Foundation of China) Grant 81302588 and Linyi Health Science Project 201616058 to Dashan Wang; XMBST Grant J00133 to Guixiu Shi; Fujian Science and Technology Project 2015D019 to Yuan Liu; and NSFC Grant 81302565 to Yan Li.

\section{References}

[1] W. M. Oldham and H. E. Hamm, "Heterotrimeric G protein activation by G-protein-coupled receptors," Nature Reviews Molecular Cell Biology, vol. 9, no. 1, pp. 60-71, 2008.

[2] S. Offermanns, "G-proteins as transducers in transmembrane signalling," Progress in Biophysics and Molecular Biology, vol. 83, no. 2, pp. 101-130, 2003.

[3] L. Klareskog, A. I. Catrina, and S. Paget, "Rheumatoid arthritis," The Lancet, vol. 373, no. 9664, pp. 659-672, 2009.

[4] D. D. D’Angelo, Y. Sakata, J. N. Lorenz et al., "Transgenic G $\alpha \mathrm{q}$ overexpression induces cardiac contractile failure in mice," Proceedings of the National Academy of Sciences of the United States of America, vol. 94, no. 15, pp. 8121-8126, 1997.

[5] G. Shi, S. Partida-Sánchez, R. S. Misra et al., "Identification of an alternative $\mathrm{G} \alpha \mathrm{q}$-dependent chemokine receptor signal transduction pathway in dendritic cells and granulocytes," Journal of Experimental Medicine, vol. 204, no. 11, pp. 2705-2718, 2007.

[6] R. S. Misra, G. Shi, M. E. Moreno-Garcia et al., "G $\alpha$ q-containing $G$ proteins regulate $B$ cell selection and survival and are required to prevent B cell-dependent autoimmunity," Journal of Experimental Medicine, vol. 207, no. 8, pp. 1775-1789, 2010.

[7] D. Wang, Y. Zhang, Y. He, Y. Li, F. E. Lund, and G. Shi, "The deficiency of $\mathrm{G} \alpha \mathrm{q}$ leads to enhanced T-cell survival," Immunology and Cell Biology, vol. 92, no. 9, pp. 781-790, 2014.

[8] Y. Wang, Y. Li, Y. He et al., "Expression of G protein $\alpha \mathrm{q}$ subunit is decreased in lymphocytes from patients with rheumatoid arthritis and is correlated with disease activity," Scandinavian Journal of Immunology, vol. 75, no. 2, pp. 203-209, 2012.

[9] S. K. Lundy, S. Sarkar, L. A. Tesmer, and D. A. Fox, "Cells of the synovium in rheumatoid arthritis. T lymphocytes," Arthritis Research and Therapy, vol. 9, no. 1, article 202, 2007.

[10] S. Alzabin and R. O. Williams, "Effector T cells in rheumatoid arthritis: lessons from animal models," FEBS Letters, vol. 585, no. 23, pp. 3649-3659, 2011.

[11] H. Schulze-Koops and J. R. Kalden, "The balance of Th1/Th2 cytokines in rheumatoid arthritis," Best Practice and Research: Clinical Rheumatology, vol. 15, no. 5, pp. 677-691, 2001.

[12] J. D. Cañete, S. E. Martínez, J. Farrés et al., "Differential Th1/Th2 cytokine patterns in chronic arthritis: interferon $\gamma$ is highly expressed in synovium of rheumatoid arthritis compared with seronegative spondyloarthropathies," Annals of the Rheumatic Diseases, vol. 59, no. 4, pp. 263-268, 2000.

[13] D. Wang, Y. Li, Y. Liu, and G. Shi, "The role of autoreactive T cell in the pathogenesis of rheumatoid arthritis and implications for T cell targeted vaccine therapy," Minerva Medica, vol. 106, no. 3 , pp. 157-167, 2015.

[14] F. C. Arnett, S. M. Edworthy, D. A. Bloch et al., "The american rheumatism association 1987 revised criteria for the classification of rheumatoid arthritis," Arthritis \& Rheumatism, vol. 31, no. 3, pp. 315-324, 1988.

[15] K. L. Kemp, S. D. Levin, P. J. Bryce, and P. L. Stein, "Lck mediates Th2 differentiation through effects on T-bet and GATA-3," Journal of Immunology, vol. 184, no. 8, pp. 4178-4184, 2010.

[16] H. Guan, P. S. Nagarkatti, and M. Nagarkatti, "Role of CD44 in the differentiation of Th1 and Th2 cells: CD44-deficiency enhances the development of Th2 effectors in response to sheep RBC and chicken ovalbumin," The Journal of Immunology, vol. 183, no. 1, pp. 172-180, 2009.

[17] W. L. van Der Graaff, A. P. A. Prins, B. A. C. Dijkmans, and R. A. W. Van Lier, "Prognostic value of Th1/Th2 ratio in rheumatoid arthritis," Lancet, vol. 351, no. 9120, article 1931, 1998.

[18] R. Gerli, O. Bistoni, A. Russano et al., "In vivo activated T cells in rheumatoid synovitis. Analysis of Th1- and Th2-type cytokine production at clonal level in different stages of disease," Clinical and Experimental Immunology, vol. 129, no. 3, pp. 549-555, 2002.

[19] S. J. Szabo, S. T. Kim, G. L. Costa, X. Zhang, C. G. Fathman, and L. H. Glimcher, "A novel transcription factor, T-bet, directs Th1 lineage commitment," Cell, vol. 100, no. 6, pp. 655-669, 2000.

[20] J. J. Goronzy and C. M. Weyand, "Rheumatoid arthritis," Immunological Reviews, vol. 204, pp. 55-73, 2005.

[21] A. P. Cope, H. Schulze-Koops, and M. Aringer, "The central role of T cells in rheumatoid arthritis," Clinical and Experimental Rheumatology, vol. 25, no. 5, supplement 46, pp. S4-S11, 2007.

[22] T. Kamradt and O. Frey, "Arthritis: where are the T cells?" Arthritis Research and Therapy, vol. 12, no. 3, article 122, 2010.

[23] C. A. Roberts, A. K. Dickinson, and L. S. Taams, "The interplay between monocytes/macrophages and $\mathrm{CD} 4^{+} \mathrm{T}$ cell subsets in rheumatoid arthritis," Frontiers in Immunology, vol. 6, article 571,2015

[24] B. Müller, U. Gimsa, N. A. Mitchison, A. Radbruch, J. Sieper, and Z. Yin, "Modulating the Th1/Th2 balance in inflammatory arthritis," Springer Seminars in Immunopathology, vol. 20, no. 12, pp. 181-196, 1998.

[25] L. A. Boule, C. G. Burke, B. M. Fenton, K. Thevenet-Morrison, T. A. Jusko, and B. P. Lawrence, "Developmental activation of the AHR increases effector CD4+ T cells and exacerbates symptoms 
in autoimmune disease-prone Gnaq $+/$ - mice," Toxicological Sciences, vol. 148, no. 2, pp. 555-566, 2015.

[26] J. Zhu and W. E. Paul, "Peripheral CD4+ T-cell differentiation regulated by networks of cytokines and transcription factors," Immunological Reviews, vol. 238, no. 1, pp. 247-262, 2010.

[27] D. Amsen, C. G. Spilianakis, and R. A. Flavell, "How are TH1 and TH2 effector cells made?" Current Opinion in Immunology, vol. 21, no. 2, pp. 153-160, 2009.

[28] A. C. Mullen, F. A. High, A. S. Hutchins et al., "Role of T-bet in commitment of TH1 cells before IL-12-dependent selection," Science, vol. 292, no. 5523, pp. 1907-1910, 2001.

[29] A. C. Mullen, A. S. Hutchins, F. A. High et al., "Hlx is induced by and genetically interacts with T-bet to promote heritable $\mathrm{T}_{H} 1$ gene induction," Nature Immunology, vol. 3, no. 7, pp. 652-658, 2002.

[30] M. H. Kaplan, Y.-L. Sun, T. Hoey, and M. J. Grusby, "Impaired IL-12 responses and enhanced development of Th2 cells in Stat4- deficient mice," Nature, vol. 382, no. 6587, pp. 174-177, 1996.

[31] D. Christie and J. Zhu, "Transcriptional regulatory networks for CD4 T cell differentiation," Current Topics in Microbiology and Immunology, vol. 381, pp. 125-172, 2014.

[32] C. M. Porter and N. A. Clipstone, "Sustained NFAT signaling promotes a Thl-like pattern of gene expression in primary murine CD4+ T cells," The Journal of Immunology, vol. 168, no. 10, pp. 4936-4945, 2002.

[33] W.-R. Park, M. Nakahira, N. Sugimoto et al., "A mechanism underlying STAT4-mediated up-regulation of IFN- $\gamma$ induction in TCR-triggered T cells," International Immunology, vol. 16, no. 2, pp. 295-302, 2004.

[34] J. Ngai, T. Methi, K. W. Andressen et al., “The heterotrimeric G-protein $\alpha$-subunit G $\alpha \mathrm{q}$ regulates TCR-mediated immune responses through an Lck-dependent pathway," European Journal of Immunology, vol. 38, no. 11, pp. 3208-3218, 2008. 


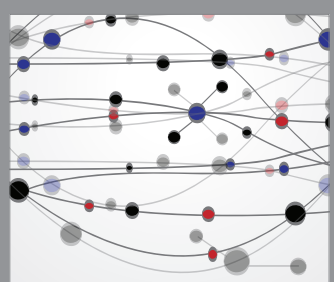

The Scientific World Journal
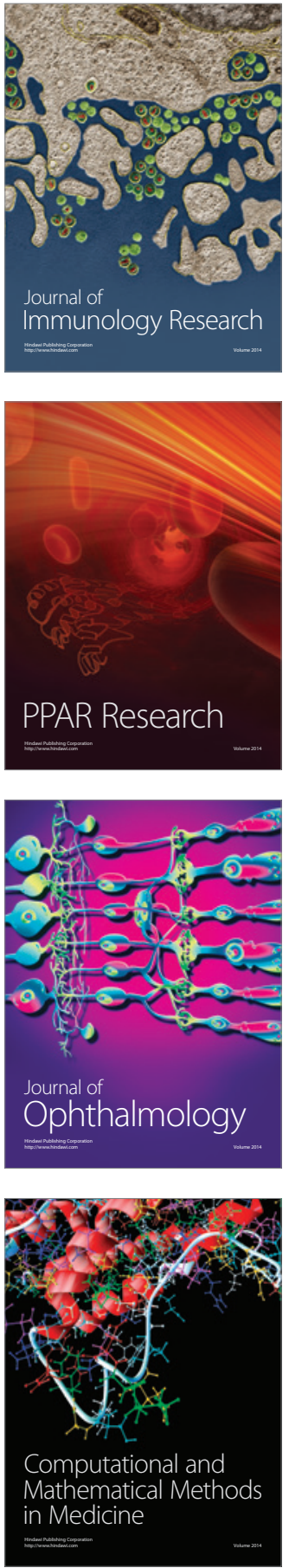

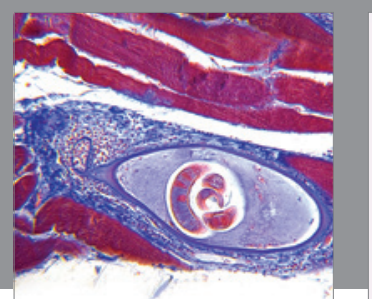

Gastroenterology Research and Practice
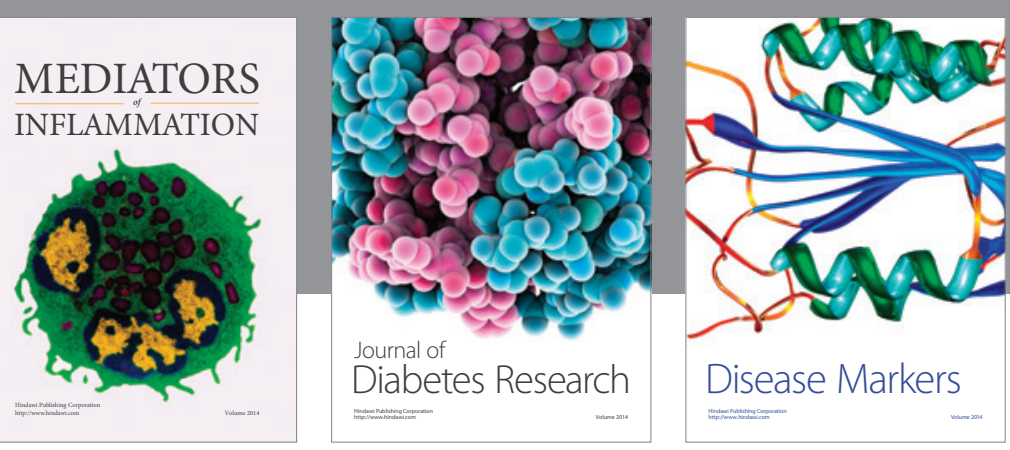

Disease Markers

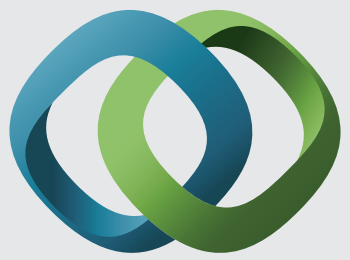

\section{Hindawi}

Submit your manuscripts at

https://www.hindawi.com
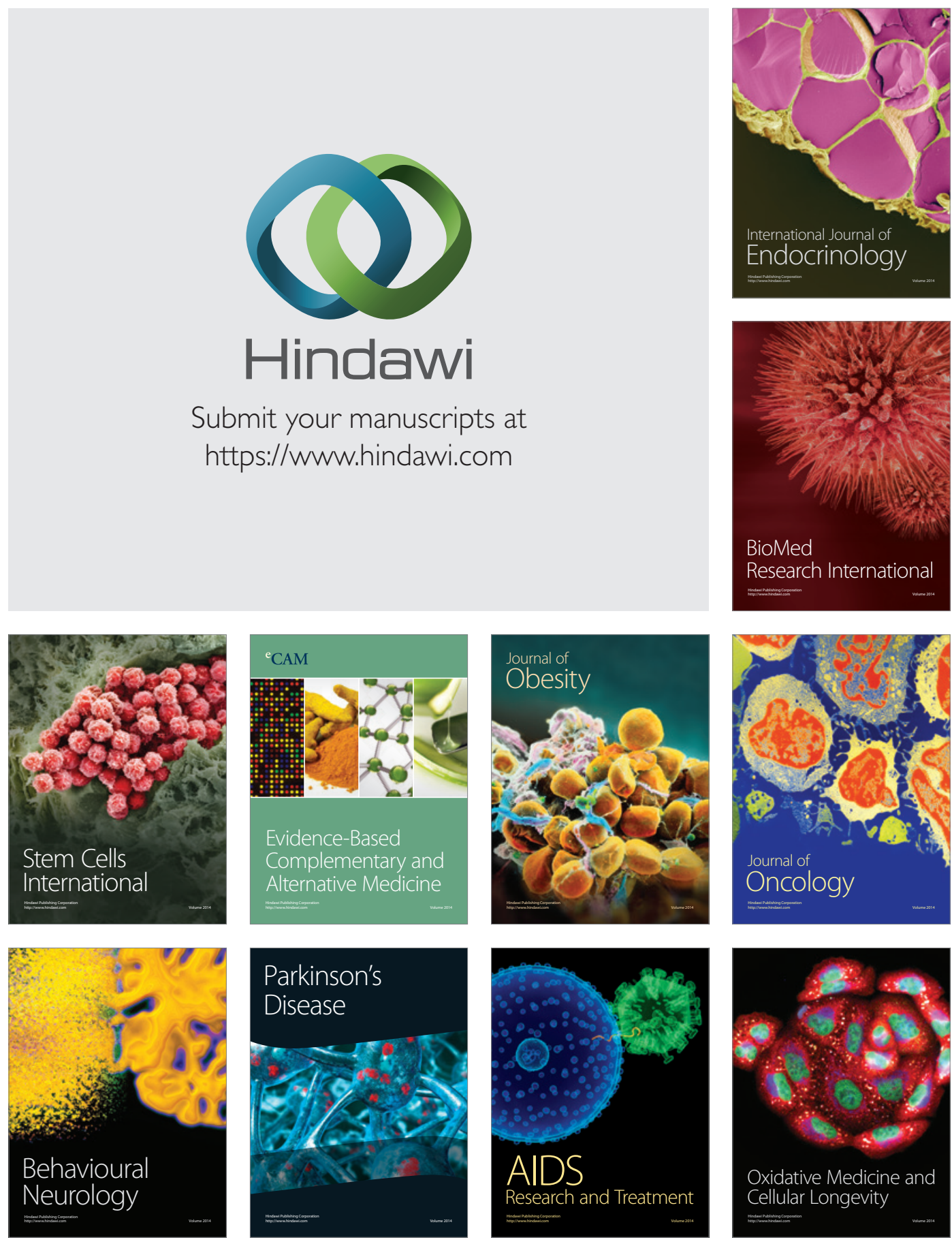